\title{
Design and Implementation of Power Efficient 8:1 Multiplexer Based on Adiabatic Logic
}

\author{
Vijendra Pratap Singh ${ }^{1}$, Dr. S. R. P. Sinha ${ }^{2}$ \\ ${ }^{1,2}$ Institute of Engineering and Technology, Sitapur Road Lucknow, India
}

\begin{abstract}
The increasing speed and complexity of today's designs implies a significant increase in the power consumption of the verylarge scale integration (VLSI) of chips. To meet this challenge, researchers have developed many different design techniques to reduce the power. Adiabatic switching principle is one of the important circuit design technique, which reduces the power consumption compared to conventional CMOS. This paper presents a 8:1 multiplexer based on adiabatic switching principle that uses a pair of complementary split-level sinusoidal power supply clocks for digital low power applications. Some standard adiabatic logic styles like PFAL, ECRL, 2n2n2p are investigated, but the proposed logic is better. The simulation is carried out in TSPICE software at $0.5 \mu m$ CMOS technology for frequency range $200 \mathrm{MHz}-800 \mathrm{MHz}$.
\end{abstract}

Keywords: Adiabatic logic, Multiplexer, PFAL, ECRL, 2n2n2p, power dissipation, power saving

\section{Introduction}

With the widespread use of mobile, hand-held and wireless electronics devices, the demands for the innovations of lowpower VLSI arise. For most of the digital circuits today, CMOS logic scheme has been the technology of choice for Implementing low-power systems. As the clock and logic speeds increase to meet the new performance requirements, the energy requirement of CMOS circuits are becoming a major concern in the design of these devices. The word adiabatic comes from a Greek word that is used to describe the thermodynamic processes. In thermodynamic process, there is no heat exchange with the environment and therefore, no energy loss in the form of dissipated heat.

In real life computing, such ideal process cannot be achieved because of the presence of the dissipative elements like resistances in the circuit. However, one can achieve very low energy dissipation by slowing down the speed of operation and only switching transistors under certain conditions. The signal energies stored in the circuit capacitances are recycled instead, of being dissipated as heat. The adiabatic logic is also known as recovery CMOS [1].

Adiabatic logic has an important advantage over the conventional CMOS, i.e. the power dissipation in the adiabatic logic is less compared to conventional CMOS.

Each power-clock cycle, as shown in fig.1, consists of four intervals. In the evaluate (E) interval, the outputs are evaluated from the stable input signals. During the hold $(\mathrm{H})$ interval, outputs are kept stable for supplying the subsequent gate with a stable input signal. Energy is recovered in the interval called recover (R). And for symmetry reasons, a wait (W) interval is inserted, as symmetric signals are easier and more efficient to be generated.

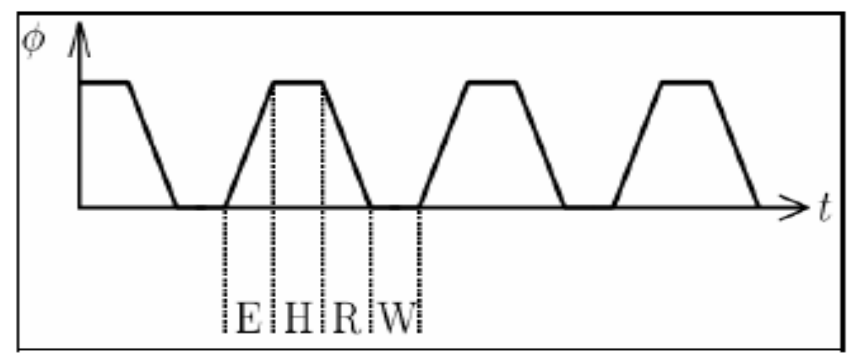

Figure 1: Scheme of the four phase power clock

In this paper, the standard adiabatic logic styles, which have been investigated are: ECRL [2] [3] [6], PFAL [2] [4] [6] and $2 \mathrm{n} 2 \mathrm{n} 2 \mathrm{p}$ [2] [5] [6]. Their general schematics are given in fig. 2, 3 and 4 .

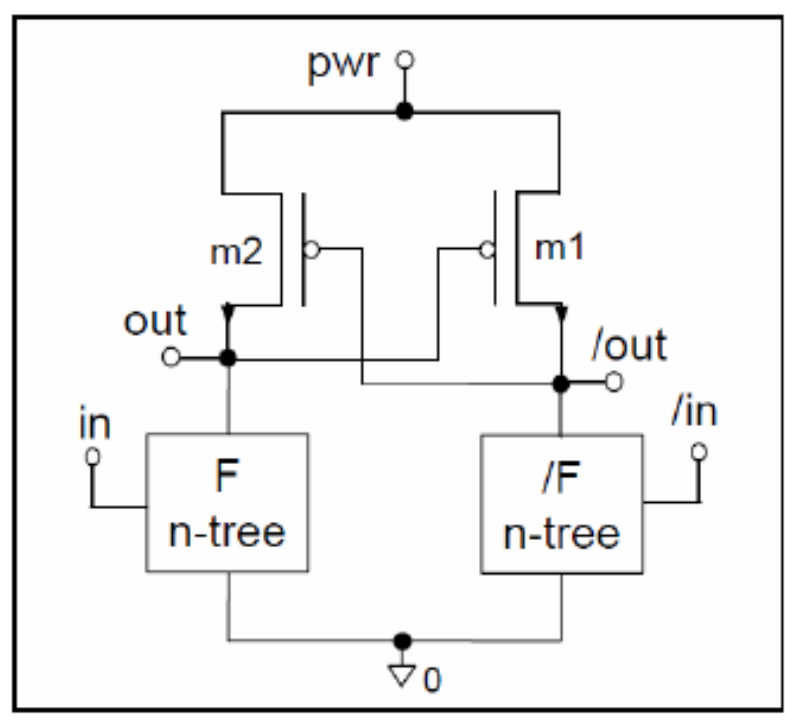

Figure 2: Schematic of ECRL 


\section{International Journal of Science and Research (IJSR) \\ ISSN (Online): 2319-7064}

Index Copernicus Value (2013): 6.14 | Impact Factor (2014): 5.611

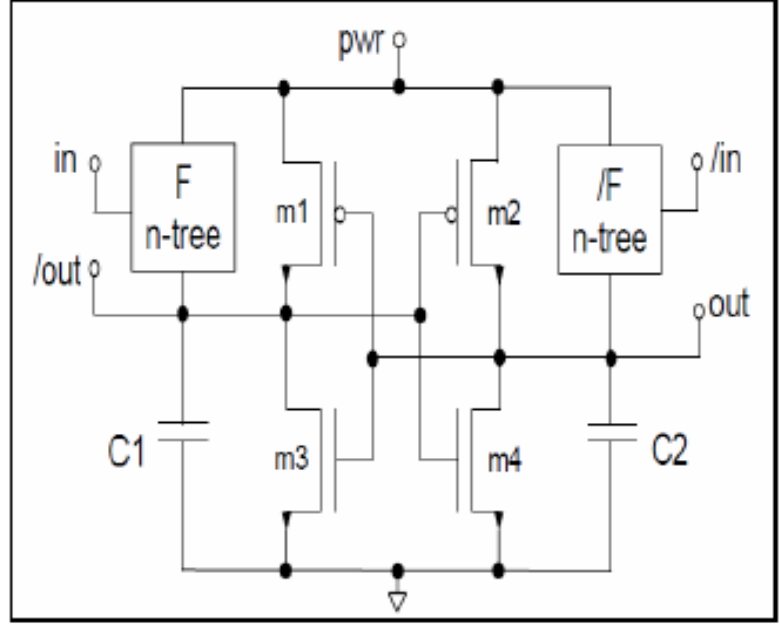

Figure 3: Schematic of PFAL

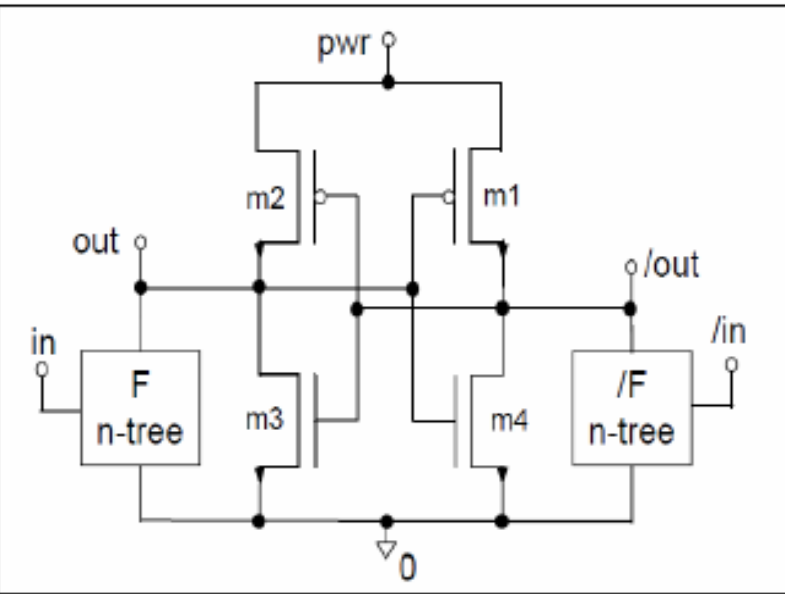

Figure 4: Schematic of 2N2N2P

This paper analyses the total power dissipation of the multiplexer circuits using the standard logic styles and proposes a new logic style with lesser power dissipation.

\section{Expressions of Multiplexer}

A multiplexer is a special type of combinational circuit which selects only one of , $\mathrm{n}^{\text {"e }}$ given data inputs and routes it to the output. The selection of one of the inputs is done by „me select inputs, with $2^{\mathrm{m}}=\mathrm{n}$.

The block diagram of 8:1 multiplexer is shown in fig. 5 .

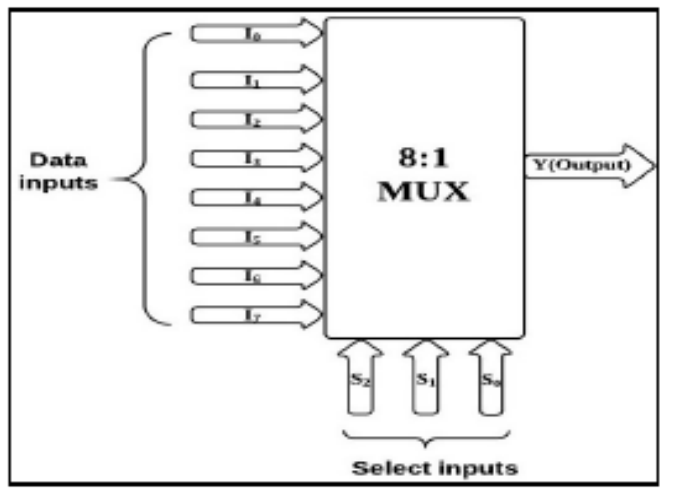

Figure 5: Block diagram of 8:1 multiplexer
Table 1 8:1 Multipleexer Truth Table

\begin{tabular}{|c|c|c|c|}
\hline \multicolumn{3}{|c|}{ Select Inputs } & Outputs \\
\hline S2 & S1 & S 0 & Y \\
\hline 0 & 0 & 0 & $\mathrm{I}_{0}$ \\
\hline 0 & 0 & 1 & $\mathrm{I}_{1}$ \\
\hline 0 & 1 & 0 & $\mathrm{I}_{2}$ \\
\hline 0 & 1 & 1 & $\mathrm{I}_{3}$ \\
\hline 1 & 0 & 0 & $\mathrm{I}_{4}$ \\
\hline 1 & 0 & 1 & $\mathrm{I}_{5}$ \\
\hline 1 & 1 & 0 & $\mathrm{I}_{6}$ \\
\hline 1 & 1 & 1 & $\mathrm{I}_{7}$ \\
\hline
\end{tabular}

From the truth table output expression can be given as:

$$
\begin{gathered}
\mathrm{Y}=\overline{\mathrm{S}}_{2} \overline{\mathrm{S}}_{1} \bar{S}_{0} \mathrm{I}_{0}+\overline{\mathrm{S}}_{2} \overline{\mathrm{S}}_{1} \mathrm{~S}_{0} \mathrm{I}_{1}+\overline{\mathrm{S}}_{2} \mathrm{~S}_{1} \bar{S}_{0} \mathrm{I}_{2}+\overline{\mathrm{S}}_{2} \mathrm{~S}_{1} \mathrm{~S}_{0} \mathrm{I}_{3} \\
+\mathrm{S}_{2} \overline{\mathrm{S}}_{1} \overline{\mathrm{S}}_{0} \mathrm{I}_{4}+\mathrm{S}_{2} \overline{\mathrm{S}}_{1} \mathrm{~S}_{0} \mathrm{I}_{5}+\mathrm{S}_{2} \mathrm{~S}_{1} \bar{S}_{0} \mathrm{I}_{6}+\mathrm{S}_{2} \mathrm{~S}_{1} \mathrm{~S}_{0} \mathrm{I}_{7} .
\end{gathered}
$$

\section{Logic for Proposed Circuit}

The first difference between proposed circuit and static CMOS logic gate is the two diodes, one from the output node to the power clock supply and another one is placed next to the NMOS logic to another power clock. Both MOSFETdiodes are used to re-cycle the charges from the output node, to improve discharging speed of internal signal nodes.

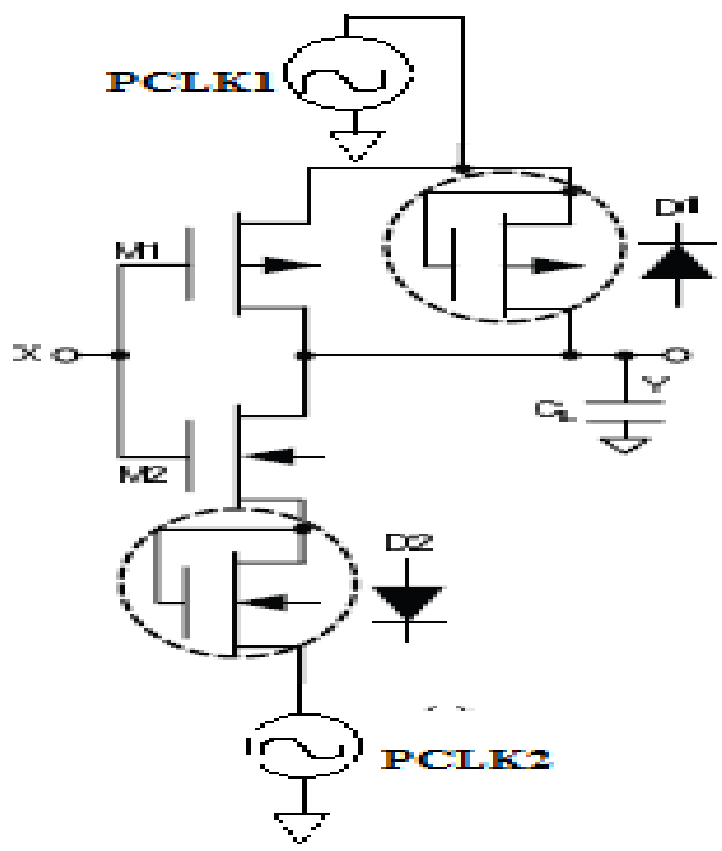

Figure 6: Proposed inverter circuit

In this inverter circuit, two sinusoidal power clocks are used, which are out of phase. During the evaluation phase of the power clocks, the potential difference is maximum between the power clocks and load capacitor is charged up to peak value and output is obtained. In the hold phase of the power clock, the charge from the load capacitor is recovered. In this way energy is recovered from the output node.

Its truth table is given in table 1. 


\section{International Journal of Science and Research (IJSR) \\ ISSN (Online): 2319-7064}

Index Copernicus Value (2013): 6.14 | Impact Factor (2014): 5.611

\section{Proposed 8:1 power efficient adiabatic multiplexer}

Figure 7 shows the proposed power efficient multiplexer based on the adiabatic logic. The simulation of the proposed logic for the multiplexer against the standard logic stylesPFAL, ECRL and 2n2n2p have been done with load capacitance $10 \mathrm{fF}$ at a frequency range $200-800 \mathrm{MHz}$. Their power consumptions are carried out at $0.5 \mu \mathrm{m}$ technology with $\mathrm{W}=1.25 \mu \mathrm{m}$ and $\mathrm{L}=0.5 \mu \mathrm{m}, \mathrm{VPCLK}=3.3 \mathrm{~V}, \mathrm{~V}=3 \mathrm{~V}$ (the input pulse voltage).

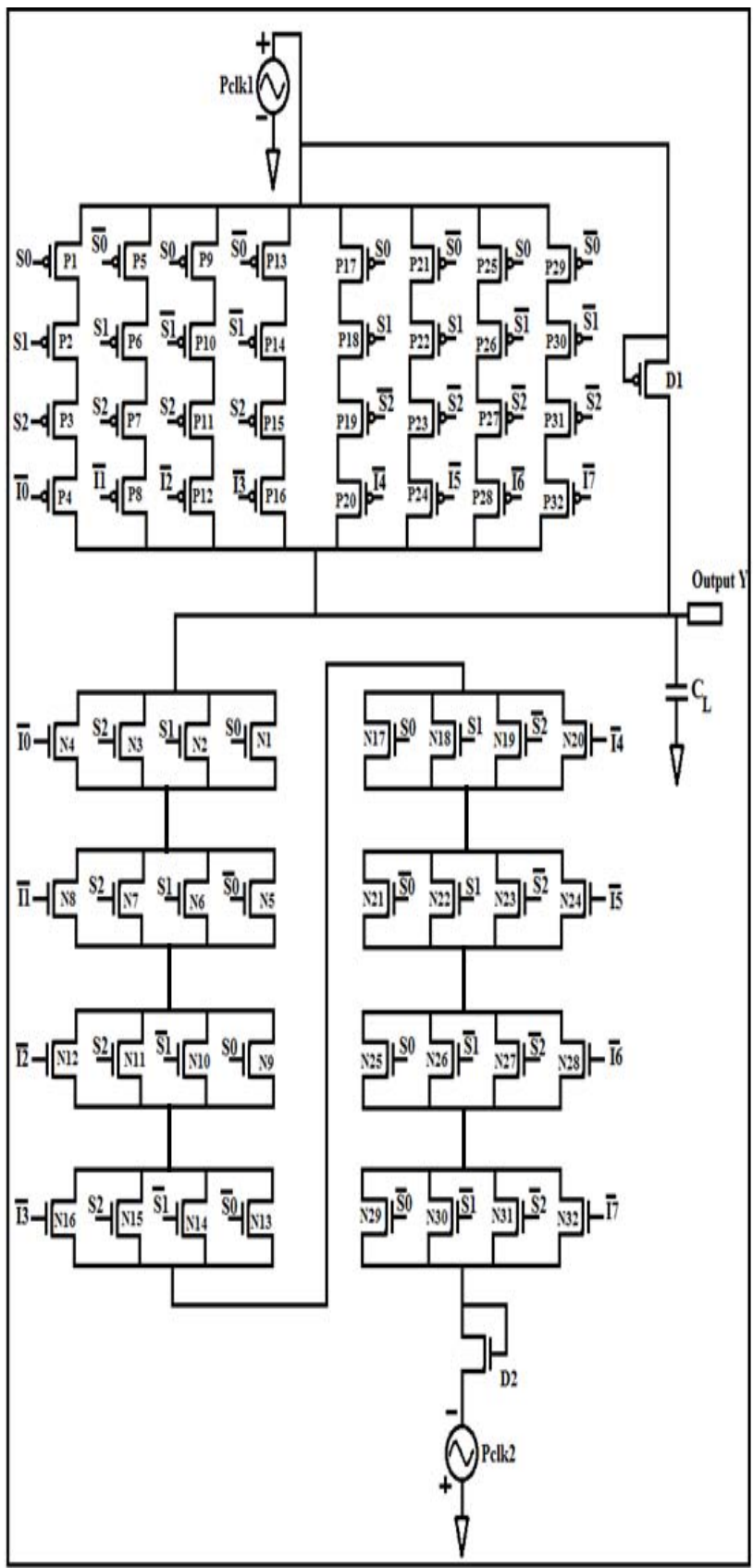

Figure7- Proposed circuit for 8:1 multiplexer

\section{Simulation Result for Proposed Multiplexer}

Figure 8 shows the simulation results of the proposed 8:1 multiplexer based on the adiabatic logic. After simulation, the output waveform obtained for the proposed circuit with respect to input $\mathbf{I}_{\mathbf{4}}$ is given in the figure.
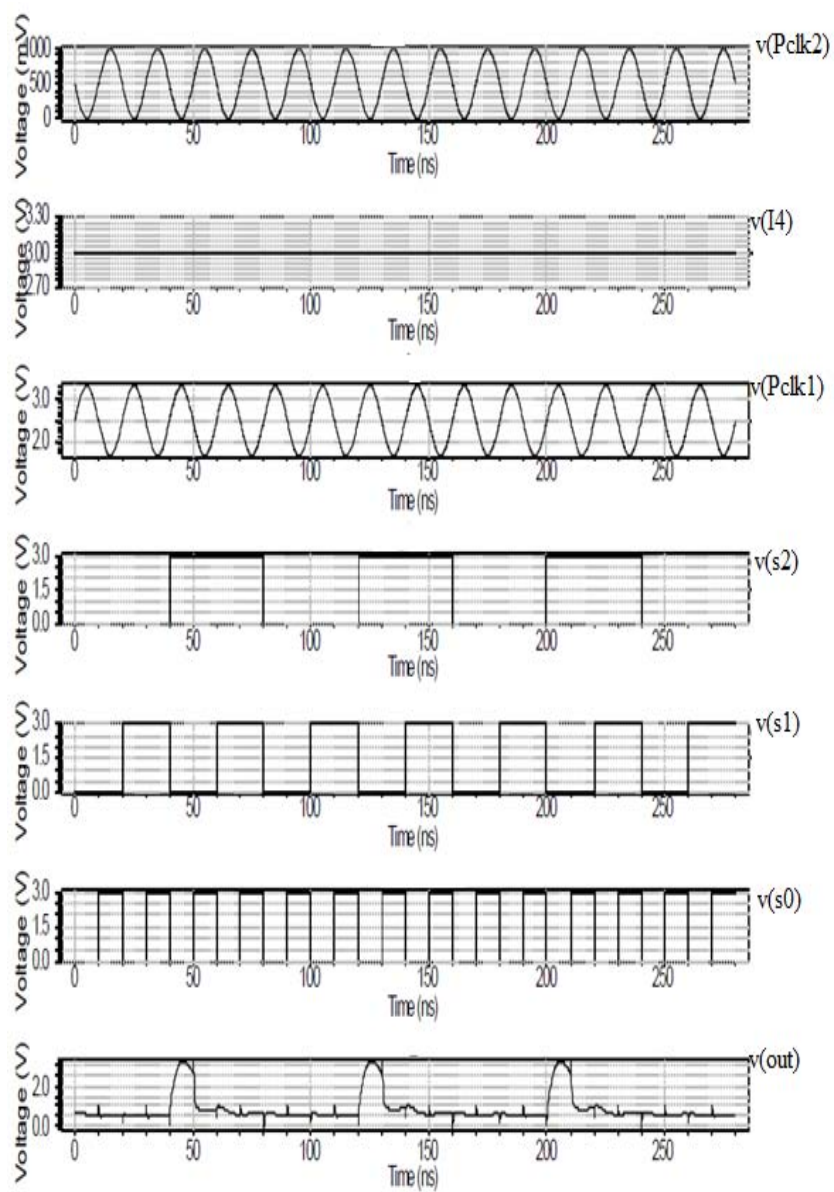

Figure 8- simulatiion results of the proposed multiplexer

6. Performance analysis of various logic styles for 8:1 multiplexer

Table 2 shows the power comparison of various logic styles and the proposed 8:1 multiplexer.

TABLE 2

\begin{tabular}{|c|c|c|c|c|c|}
\hline Logic & $2 \mathrm{n} 2 \mathrm{n} 2 \mathrm{p}$ & ECRL & PFAL & $\begin{array}{l}\text { Previous } \\
\text { circuit } \\
\text { Result }\end{array}$ & $\begin{array}{c}\text { Proposed } \\
\text { circuit } \\
\text { result }\end{array}$ \\
\hline Transistor count & 68 & 66 & 68 & 66 & 66 \\
\hline $\begin{array}{c}\text { Total power } \\
\text { dissipation( } \mu \text { watts) } \\
\text { at } 400 \mathrm{MHz}\end{array}$ & 54.295 & 41.721 & 30.02 & 16.8 & 9.9 \\
\hline $\begin{array}{c}\text { Total power } \\
\text { dissipation( } \mu \text { watts) } \\
\text { at } 800 \mathrm{MHz}\end{array}$ & 98.794 & 83.370 & 59.849 & 31.52 & 14.1 \\
\hline
\end{tabular}




\section{International Journal of Science and Research (IJSR) \\ ISSN (Online): 2319-7064}

Index Copernicus Value (2013): 6.14 | Impact Factor (2014): 5.611

From the table 2, it is clear that the proposed adiabatic multiplexer consumes less power compared with the previously proposed circuit. So this proposed circuit is preferred for the power efficient digital logic circuit designs.

\section{Conclusion}

This paper has described a simulation of power efficient 8:1 multiplexer based on adiabatic logic. By implementing the adiabatic charging and energy recovery theory, the proposed circuit gives the lowest result in power dissipation of all the simulated adiabatic multiplexers. The power dissipation measurement by TSPICE proved that this approach lowers the power dissipation. The design principle can also be used for designing more complicated adiabatic CMOS circuits and its logic schemes can be a viable candidate for ultra-low energy computing.

\section{References}

[1] S. Vijayakumar and B. Karthikeyan, "Mixed style of Low Power Multiplexer Design for Arithmetic Architectures using 90nm Technology", Proceedings of the 12th international conference on Networking, VLSI and signal processing (ICNVS), pp. 83-87, February 2010.

[2] P.Teichmann, "Adiabatic Logic Future Trends and Future Level Perspective", Springer Publication, 2012 Edition.

[3] Yong Moon and Deog-Kyoon Jeong, “An Efficient Charge Recovery Logic Circuit", IEEE Journal of Solid-State Circuits, Vol. 31 Issue 4, pp. 514-522, April 1996.

[4] A. Vetuli, S. Di Pascoli, L.M. Reyneri, "Positive Feedback in adiabatic logic", Electronics Letters, Vol. 32 Issue 20, pp. 1867-1869, September 1996.

[5] A. Kramer, J.S. Denker, B. Flower, J. Moroney, "2nd order adiabatic computation with $2 \mathrm{~N}-2 \mathrm{P}$ and $2 \mathrm{~N}-2 \mathrm{~N} 2 \mathrm{P}$ logic circuits", Proceedings of the International Symposium on Low power design (ISLPED), pp. 191196, April 1995.

[6] Ettore Amirante, Agnese Bargagli-Sto, Jurgen Fischer,Giuseppe Iannaccone, and Doris SchmittLandsiedel, "Variations of the Power Dissipation in Adiabatic Logic Gates", International Workshop on Power And Timing Modeling, Optimization and Simulation (PATMOS), pp. 9.1.1-9.1.10 , September 2001.

[7] Richa Singh and Rajesh Mehra, "Power Efficient Design of Multiplexer using Adiabatic Logic", International Journal of Advances in Engineering \& Technology (IJAET), Vol. 6 Issue 1, pp. 246-254, March 2013

[8] N. Anuar, Y. Takahashi and T. Sekine, "Two phase clocked adiabatic static logic circuit: a proposal for digital low power applications," Proc. IEICE Gen. Conf., p.102, Mar. 2009.

[9] Y. Takahashi, Y. Fukuta, T. Sekine and M. Yokoyama, "2PADCL : Two phase drive adiabatic dynamic CMOS logic," Proc. IEEE APCCAS, pp.1486-1489, Dec. 2006.

\section{Author Profile}

Vijendra Pratap Singh, received the B.Tech degree in Applied Electronics and Instrumentation Engineering from Skyline Institute of Engineering and Technology, Greater Noida, Uttar Pradesh, India. He is currently final year student of M.Tech in MicroElectronics from, Institute of Engineering and Technology, Lucknow. His area of interest includes Micro-Electronics and VLSI.

Dr. S.R.P Sinha received the B.Tech degree from, Ranchi University in 1981 and M.Tech degree from, University of Roorkee in 1984. He received the Ph.D degree from Lucknow University in 2004. He is presently working as Associate Professor in Department of Electronics Engineering, in Institute of engineering and technology, Lucknow. His area of interest includes Solid State Electronic Devices, Micro-Electronics and VLSI. 